\title{
Diabetes as a Risk Factor Hepatic Encephalopathy among Egyptian Cirrhotic Patients Mohammed Noshi El-Alfy ${ }^{1}$, Khaled Masoud Dousoky ${ }^{1}$, Ahmed Anwer Mohammed Shaheen ${ }^{2}$, Mohammed Abdel-Hassib ${ }^{1}$ and Abdullah Mahfouz Abd Elwahed ${ }^{1}$ \\ ${ }^{1}$ Department of Internal Medicine, Faculty of Medicine, Al-Azhar University, ${ }^{2}$ \\ Clinical pathology and microbiology, Faculty of Medicine, Zagazig University. \\ Corresponding author: Abdullah Mahfouz Abd Elwahed,email: abdoomahfouz04@gmail.com
}

\begin{abstract}
Background: Hepatic encephalopathy (HE) is one of the leading consequences among patients with cirrhotic liver, which influence more than $35 \%$ of these patients. It was established that more than $95 \%$ of cirrhotic patients were associated with glucose intolerance and approximately 33\% of them had type 2 diabetes mellitus (DM). This investigation was conducted to evaluate the possible association between DM and the development of HE.

Objective: this study was designed to examine the association of DM with the prevalence and severity of HE in Egyptian patients with decompensated cirrhosis.

Patients and methods: This study was carried out prospectively on 100 patients presented with HE. Those further had been classified into diabetic (60 patients group 1) and non-diabetic (40 patients group 2). All patients in this study were subjected to a thorough assessment of history taking, thorough physical examination, laboratory investigations including complete blood picture, kidney and liver function tests, viral HBsAg and HCVAb, serum sodium, potassium, calcium and magnesium, serum ammonia levels, fasting and glycosylated hemoglobin (HbA1C \%) and abdominal ultrasonography. Results: Diabetic patients showed a higher incidence of Grades, III, and IV of HE compared to the non-diabetic group with $\mathrm{p}$ value $<0.0001$ for each grade. Furthermore, there was a statistically significant difference between both groups regarding the Child-Pough classification. A statistically significant positive correlations between fasting blood sugar level, and glycosylated hemoglobin with HE grades $(r=0.430$ and $p=0.0006),(r=0.314, p=$ 0.0145 ) respectively among diabetic patients group 1. Conclusions: Egyptian diabetic patients have a potential risk of developing HE among cirrhotic liver patients relative to non-diabetic patients.
\end{abstract}

Keywords: diabetes mellitus, hepatic encephalopathy and liver cirrhosis.

\section{INTRODUCTION}

Egypt is one of the most prevalent nations which suffered from the marvelous increase in the number of chronic liver diseases ${ }^{(\mathbf{1})}$. Hepatic encephalopathy is one of the leading consequences among patients with cirrhotic liver, which influence more than $35 \%$ of these patients (2). Noteworthy, the underlying neurological sequences of $\mathrm{HE}$ varied from minimal behavioral aberration up to deep coma and even death ${ }^{(3)}$.

Some cirrhotic patients are recognized to be at high risk of HE relative to other candidates. For instance, those with history of previous attacks, hyponatremia, impaired liver function, and diabetic patients (4). Hereafter, it was established that more than $95 \%$ of cirrhotic liver patients were associated with glucose intolerance and approximately $33 \%$ had type 2 diabetes mellitus (T2DM) ${ }^{(5,6)}$. Additionally, not only it did macerate the prognosis of cirrhosis, but it also had a major role in developing hepatocellular carcinoma ${ }^{(7)}$. Consequently, hepatogenous diabetes may be evolved as a sequel of cirrhosis. Besides, the cumulative deprivation of beta-cell insulin secretion along with accretion of the insulin resistance were the risk factors for non-alcoholic fatty liver disease and $\mathrm{T} 2 \mathrm{DM}^{(\mathbf{8})}$.
Not only did diabetes have a significant role in liver cirrhosis, but it also played a considerable function in $\mathrm{HE}$ evolving ${ }^{(9)}$. The main etiopathology of HE is raising of serum ammonia owed to the reduction capacity of ammonia metabolism as a resultant effect of impaired liver function ${ }^{(10)}$. On the one hand, diabetic patients suffered from excess gastric transient and orocecal period along with overgrowth of the intestinal bacteria and glutamase activity. Moreover, insulin resistance promotes the breakdown of the muscles and production of ammonia. Additionally, these patients usually are associated with diabetic gastropathy, which lead to chronic constipation ${ }^{(5)}$. The sequent impact of such mechanisms is the massive increase in the amount of ammonia, and systemic inflammation, which reverberated dramatically in the development of $\mathrm{HE}^{(11}$, 12).

\section{AIM OF THE STUDY}

Throughout literature search, there was a paucity of studies discussed the association between diabetes mellitus and distinct complications of decompensated liver cirrhosis. However, neither of these studies evaluated this relationship among the Egyptian population. Thereafter, this investigation was conducted 
to evaluate the possible association between diabetes mellitus and the development of HE.

\section{PATIENTS AND METHODS}

The current study was implemented in coordination with the guidelines of the Declaration of Helsinki.

Ethical approval was gained according to the recommendations of Ethics Unite, Faculty of Medicine, Al-Azhar University, Cairo, Egypt. The clinical steps and possible repercussions were plainly demonstrated for all candidates. All patients or their legal trustee assigned an informed consent before the enrollment in the study.

\section{Study design}

It is a prospective comparative case-control study, which was implemented throughout the period between March 2017 and March 2018 at Bab El-Sheria University Hospital, AL-Azhar University, and El-Ahrar Teaching Hospital.

\section{Inclusion criteria}

Patients with liver cirrhosis, which was proven by clinical features, laboratory investigations, and radiological evaluation along with decompensation evidence in the term of complications such as jaundice, ascites and HE were enrolled in the study. Of them, candidates with DM which confirmed either if the patients were previously on oral hypoglycemic medications or insulin or based on laboratory investigations when the fasting blood glucose $\geq 126$ $\mathrm{mg} / \mathrm{dL}$ on 2 sequential days or when $\mathrm{HbA} 1 \mathrm{c}$ of $\geq 6.5 \%$ were assorted as the case group.

\section{Exclusion criteria}

We omitted participants with confusional states other than hepatic encephalopathy, patients who had a history of porto-systemic shunt operation, use of psychotropic, antiepileptic drugs, alcoholism, and other substance abuse. Additionally, we outed patients who were not known to be diabetic (by history) but on presentation with HE (at time of patient inclusion) were discovered for the first time to suffer from hyperglycemia. Eventually, patients with dementia, chronic neuropsychiatric disorders, active malignancies and acute or chronic inflammatory disorders were outed.

\section{Patients clinical and laboratory evaluation}

All candidates were subordinated to through history taking with further concern to reveal the onset, duration, and course of the cirrhotic liver, and DM with focusing on the precipitating factors of HE. Consequently, we performed general and abdominal examination to assess the manifestations of liver cell failure (e.g. jaundice, pallor, ascites, hepatomegaly, splenomegaly, lower limb edema and asterixis) as well as grading of HE. The severity of HE was graded based on the clinical manifestations ${ }^{(\mathbf{1 3})}$.

To ensure the optimal assessment, all participants were submitted to liver function tests including; serum albumin, prothrombin time and INR. In addition, liver enzymes, total and direct bilirubin, renal function test (blood urea and serum creatinine) and Serum electrolytes (with their normal reference ranges) including $\mathrm{Na}^{+}(135-$ 147 meq. /L), $\mathrm{K}^{+}$(3.6 -5.2 meq. /L), $\mathrm{Ca}^{+2}$ (9.1 -10.2 $\mathrm{mg} / \mathrm{dl})$ and $\mathrm{Mg}^{+2}$ (1.7 -2.2 $\left.\mathrm{mg} / \mathrm{dl}\right)$. Also, blood profile, fasting blood sugar, glycosylated hemoglobin (HbA1c\%), Fasting Venous Blood Ammonia level (FVBAM), and viral markers were implemented for all patients.

Child-Pugh classification was done on admission by using the parameters of serum bilirubin, serum albumin, prothrombin concentration, hepatic encephalopathy, and ascites according to Child-Pugh score system ${ }^{(\mathbf{1 4})}$.

\section{Radiological evaluation}

Pelvi-abdominal ultrasonography to assess the chronic liver diseases and its complication including; the diagnosis of cirrhosis, evidence of portal venous hypertension defined as portal vein diameter $\geq 12 \mathrm{~mm}$ (the normal mean portal vein diameter $=11 \pm 2 \mathrm{~mm}$ ) and splenic size (splenomegaly was diagnosed if the maximal bipolar splenic diameter $\geq 13 \mathrm{~cm}$ ), texture homogeneity. The presence or absence of ascites and its quantity (identified as peritoneal echo free spaces in one or more of typical sites including; pelvis, hepatorenal pouch and/or leinorenal pouch).

\section{Statistical analysis}

Analysis of data was done by computer using SPSS statistics desktop, V21.0.0. A Word processing, database and statistics program. The data, which elucidated normal distribution was notified as mean and standard deviation (SD). Non-paired two and three groups were compared using student T-test and ANOVA test, respectively. Qualitative variables were reported in the form of number and percentage and its particular groups were compared using either Chi-square test or Z-test. Eventually, to appreciate the association between blood glucose parameters and liver parameters, Spearmann rank correlation was used. Two-sided $\mathrm{p}$-value showed statistical significance at the value of $<0.05$. 


\section{RESULTS}

Out of 100 cirrhotic liver patients were fulfilled the criteria to be included in the study, 60 diabetic participants were enrolled in the case group, whilst 40 candidates were enrolled in the control group with a mean age of $56.7 \pm 9.38$ years, and $50.65 \pm 14.54$ years, respectively (Table 1). Having the distribution of HE grades, diabetic patients showed higher incidence of Grades II, III, and IV of HE compared to the non- diabetic group with p-value of $<0.0001$ for each grade. Furthermore, there were statistically significant difference $(\mathrm{p}<0.0001)$ between both groups regarding the Child-Pough classification. Patients of diabetic group showed a lower incidence of Grades A and B. On the contrary, patients of diabetic group showed a higher incidence of Grade $\mathrm{C}$ of Child-Pough classification compared to the non-diabetic group $(n=42,85.7 \%$ vs. $n$ $=7,14.3 \%$ respectively). (Table. 2 , and figures 1 , and 2 ).

\begin{tabular}{|c|c|c|c|c|c|c|c|}
\hline \multicolumn{2}{|c|}{ Variable } & \multirow{2}{*}{$\begin{array}{c}\begin{array}{c}\text { All cases }(N . \\
=100)\end{array} \\
54.28 \pm 12.24\end{array}$} & \multirow{2}{*}{$\begin{array}{c}\text { Group I } \\
\text { Diabetics }(N \text {. } \\
=60) \\
56.7 \pm 9.38 \\
\end{array}$} & \multirow{2}{*}{$\begin{array}{c}\text { Group II } \\
\text { Non-diabetics } \\
(N .=40) \\
\mathbf{5 0 . 6 5} \pm \mathbf{1 4 . 5 4} \\
\end{array}$} & \multirow{2}{*}{$\begin{array}{c}\begin{array}{c}\text { t- } \\
\text { value }\end{array} \\
\mathbf{- 2 . 4 8 5}\end{array}$} & \multirow{2}{*}{$\begin{array}{c}\begin{array}{c}\text { p- } \\
\text { value }\end{array} \\
0.015 \\
\end{array}$} & \multirow{2}{*}{\begin{tabular}{|c|} 
Sig. \\
S \\
\end{tabular}} \\
\hline Age (years) & Mea & & & & & & \\
\hline \multirow[t]{2}{*}{ Gender } & Female & $48(48.0 \%)$ & $28(46.7 \%)$ & $20(50.0 \%)$ & \multirow[t]{2}{*}{0.107} & \multirow[t]{2}{*}{0.744} & NS \\
\hline & Male & $52(52.0 \%)$ & $32(53.3 \%)$ & $20(50.0 \%)$ & & & \\
\hline
\end{tabular}

Table (2): Distribution of HE grades among patients of both studied groups

\begin{tabular}{|c|c|c|c|c|c|c|c|c|c|}
\hline \multirow{4}{*}{ Diabetic patients $(\mathrm{n}=60)$} & \multicolumn{6}{|c|}{ Hepatic Encephalopathy Grade } & \multirow[t]{2}{*}{ Chi-squared } & \multirow{4}{*}{\begin{tabular}{|c|} 
p-value \\
\\
\\
0.0001
\end{tabular}} & \multirow{4}{*}{$\begin{array}{c}\text { significance } \\
\text { S. }\end{array}$} \\
\hline & \multicolumn{2}{|c|}{ II $(\mathbf{n}=33)$} & \multicolumn{2}{|c|}{ III $(n=35)$} & \multicolumn{2}{|c|}{ IV $(n=32)$} & & & \\
\hline & n. & $\%$ & n. & $\%$ & n. & $\%$ & \multirow{3}{*}{22.402} & & \\
\hline & 11 & 33.3 & 20 & 57.1 & 29 & 90.6 & & & \\
\hline Non-Diabetic patients $(n=40)$ & 22 & 66.7 & 15 & 42.9 & 3 & 9.4 & & \multirow{2}{*}{ p-value } & \\
\hline & \multicolumn{6}{|c|}{ Child-Pough Grade } & Chi-squared & & significance \\
\hline & \multicolumn{2}{|c|}{$A(n=6)$} & \multicolumn{2}{|c|}{$B(n=45)$} & \multicolumn{2}{|c|}{$C(n=49)$} & \multirow{4}{*}{26.481} & \multirow{4}{*}{$\begin{array}{c}< \\
0.0001\end{array}$} & \multirow{4}{*}{ S. } \\
\hline & n. & $\%$ & n. & $\%$ & n. & $\%$ & & & \\
\hline Diabetic patients $(n=60)$ & 2 & 33.3 & 16 & 35.6 & 42 & 85.7 & & & \\
\hline Non-Diabetic patients $(n=40)$ & 4 & 66.7 & 29 & 64.4 & 7 & 14.3 & & & \\
\hline
\end{tabular}

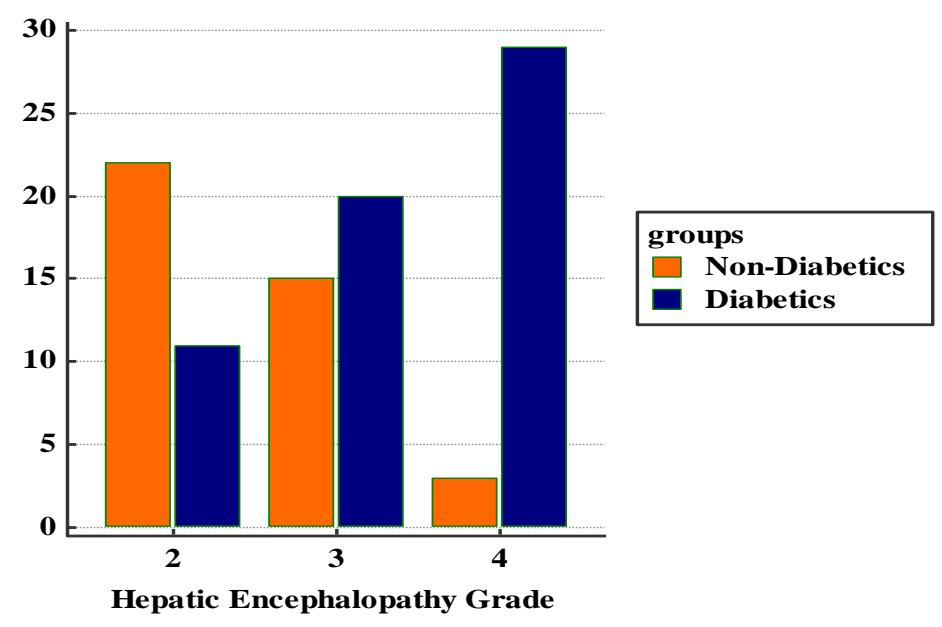

Figure (1): Distribution of HE grades among patients of both studied groups 


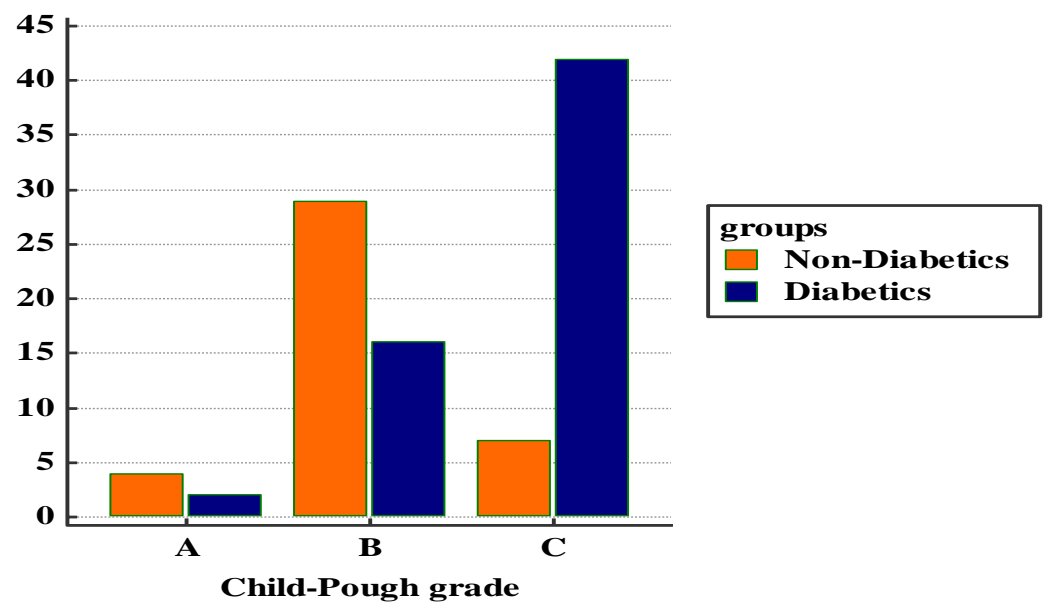

Fig. (2): Distribution of HE grades among patients of both studied groups

There was statistically significant increased glucose homeostasis parameters $(\mathrm{P}=0.001)$, serum albumin $(\mathrm{P}=0.016)$, total \& direct bilirubin $(\mathrm{P}=0.003)$, INR $(\mathrm{P}=0.001)$, FVBAM $(\mathrm{P}=0.002)$, Creatinine $(\mathrm{P}=0.002)$, urea $(\mathrm{P}=0.003), \mathrm{Na}^{+}$ $(\mathrm{P}=0.004), \mathrm{K}^{+}(\mathrm{P}=0.03), \mathrm{Mg}^{+2}(\mathrm{P}=0.044)$, corrected total calcium $(\mathrm{P}=0.011)$ and platelet count $(\mathrm{P}=0.046)$ among subjects of group I compared to those of group II. However, there was no statistically significant difference detected among subjects of group I vs. group II regarding the following variables alanine transferase (ALT) $(\mathrm{P}=0.554)$, aspartate transaminase (AST) $(\mathrm{p}=0.735)$ and hemoglobin $(\mathrm{Hb})(\mathrm{p}=0.535)$. (Table .3)

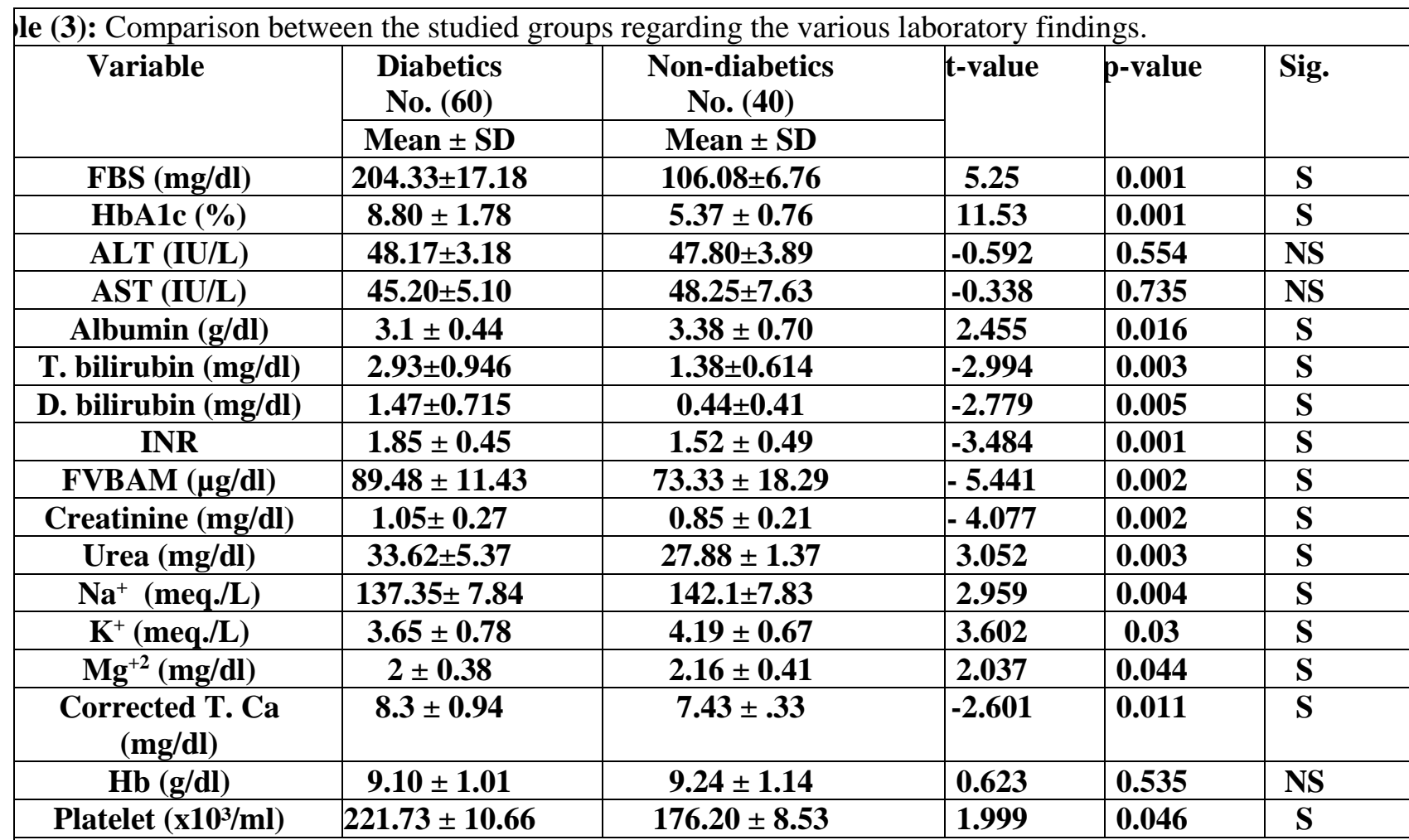

Abbreviations; $\mathrm{FBS}=$ Fasting blood sugar, $\mathrm{HBA} 1 \mathrm{C}=$ glycosylated hemoglobin, $\mathrm{ALT}=$ alanine transaminase, AST, aspartate transaminase, $\mathrm{T}=$ total, $\mathrm{D}=$ Direct, FVBAM= Fasting Venous Blood Ammonia level, $\mathrm{Hb}=$ hemoglobin 
Correlation analyses between fasting blood sugar (FBS) and various clinical, laboratory and radiological variables among the diabetic patients.

A statistically significant positive correlations between FBS level with the following variables; HE grades $(r=0.430, p=0.0006)$, Child score $(r=0.374$, $\mathrm{p}=0.002)$, ALT $(\mathrm{r}=0.459, \mathrm{p}=0.0002)$, total bilirubin $(\mathrm{r}=$ $0.381, \mathrm{p}=0.002)$, and FBVAM $(\mathrm{r}=0.390, \mathrm{p}=0.001)$ were detected. Additionally, statistically significant negative correlation between FBS level with the platelet count ( $\mathrm{r}=$ $-0.310, \mathrm{p}=0.0159)$ was detected. On the other hand, no statistically significant correlations were detected between FBS and all of the following variables; AST, serum Albumin, direct bilirubin, creatinine, blood urea, all electrolyte profile \& $\mathrm{Hb}$ levels.

Correlation analyses between $\mathrm{HbA} 1 \mathrm{c} \%$ and various clinical, laboratory and radiological variables among the diabetic patients revealed a significant positive correlation with HE grades $(r=0.314, p=0.0145)$ while the correlation with the remaining variables was insignificant (table 4) (Figures 3, and 4).

Table (4) : Correlations between FBS \& HbA1c\% with various clinical, laboratory and radiological variables among the diabetic subjects within group I

\begin{tabular}{|c|c|c|c|c|c|c|}
\hline \multirow[b]{2}{*}{ variable } & \multicolumn{2}{|c|}{ FBS (mg/dl) } & \multirow{2}{*}{ Significance } & \multicolumn{2}{|c|}{ HbA1c\% } & \multirow{2}{*}{ ignificance } \\
\hline & r value & P value & & r value & P value & \\
\hline HE grade & $\mathbf{0 . 4 3 0}$ & 0.0006 & $\mathbf{S}$ & 0.314 & b.0145 & $\mathbf{S}$ \\
\hline Chlid score & 0.374 & 0.002 & $\mathbf{S}$ & 0.082 & 0.5341 & NS \\
\hline ALT (IU/L) & 0.459 & \begin{tabular}{|l|}
0.0002 \\
\end{tabular} & $\mathbf{S}$ & 0.102 & 0.4379 & NS \\
\hline AST (IU/L) & 0.165 & 0.2084 & NS & 0.021 & 0.8755 & NS \\
\hline s. Albumin (g/dl) & -0.075 & 0.5668 & NS & -0.193 & 0.1406 & NS \\
\hline T. bilirubin (mg/dl) & 0.381 & 0.002 & $\mathbf{S}$ & 0.149 & 0.2566 & NS \\
\hline D. bilirubin (mg/dl) & -0.136 & $\mathbf{0 . 3 0 1 3}$ & NS & -0.223 & 0.0865 & NS \\
\hline INR & 0.337 & 0.008 & $\mathbf{S}$ & 0.086 & 0.5148 & NS \\
\hline FBVAM $(\mu \mathrm{g} / \mathrm{dl})$ & 0.390 & 0.001 & $\mathbf{S}$ & 0.123 & 0.3481 & NS \\
\hline S. creatinine (mg/dl) & 0.074 & 0.5729 & NS & 0.340 & 0.0780 & NS \\
\hline S. uera $(\mathrm{mg} / \mathrm{dl})$ & 0.030 & \begin{tabular}{|l|}
0.8224 \\
\end{tabular} & NS & 0.097 & 0.4604 & NS \\
\hline $\mathrm{Na}^{+}(\mathrm{meq} . / \mathrm{L})$ & 0.018 & \begin{tabular}{|l|}
0.8905 \\
\end{tabular} & NS & 0.235 & 0.0704 & NS \\
\hline $\mathbf{K}^{+}(\mathbf{m e q} . / \mathrm{L})$ & 0.133 & \begin{tabular}{|l|}
0.3103 \\
\end{tabular} & NS & 0.086 & 0.5133 & NS \\
\hline $\mathrm{Mg}^{+2}$ (mg/dl) & 0.117 & \begin{tabular}{|l|l|}
0.3723 \\
\end{tabular} & NS & 0.156 & 0.2344 & NS \\
\hline corrected $\mathrm{Ca}^{+2}(\mathrm{mg} / \mathrm{dl})$ & 0.137 & 0.2971 & NS & 0.071 & 0.5897 & NS \\
\hline Hb (g/dl) & 0.084 & 0.5234 & NS & -0.230 & 0.0772 & NS \\
\hline platlete $\left(\times 10^{3} / \mu \mathrm{L}\right)$ & -0.310 & \begin{tabular}{|l|}
0.0159 \\
\end{tabular} & $\mathbf{S}$ & 0.181 & 0.1673 & NS \\
\hline Degree of Ascitis & 0.291 & 0.0243 & $\mathbf{S}$ & 0.264 & 0.0614 & NS \\
\hline
\end{tabular}

Abbreviations; FBS= Fasting blood sugar, $\mathrm{HBA} 1 \mathrm{C}=$ glycosylated hemoglobin, ALT $=$ alanine transaminase, AST, aspartate transaminase, $\mathrm{T}=$ total, $\mathrm{D}=$ Direct, $\mathrm{S}=$ serum, FVBAM= Fasting Venous Blood Ammonia level, $\mathrm{Hb}=$ hemoglobin

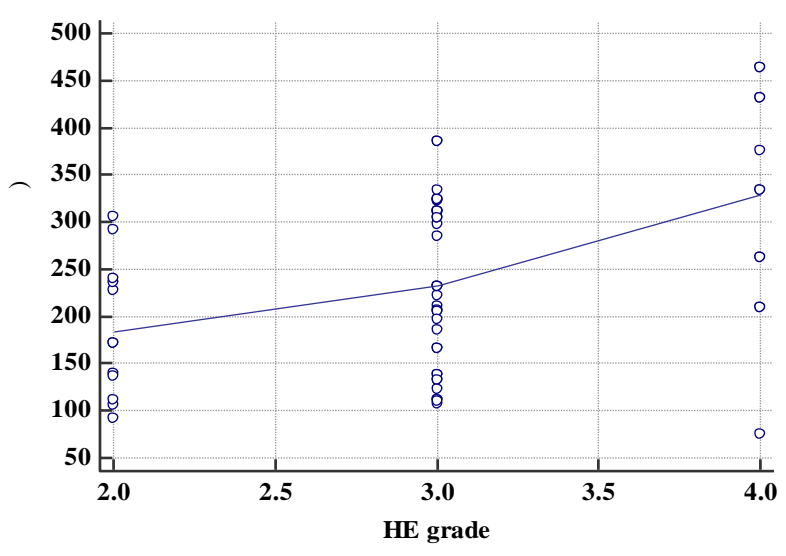

Fig. (3): Scatter diagram shows the significant + ve correlation between FBS \& HE grades among patients of group I. 
Diabetes as a Risk Factor Hepatic Encephalopathy...

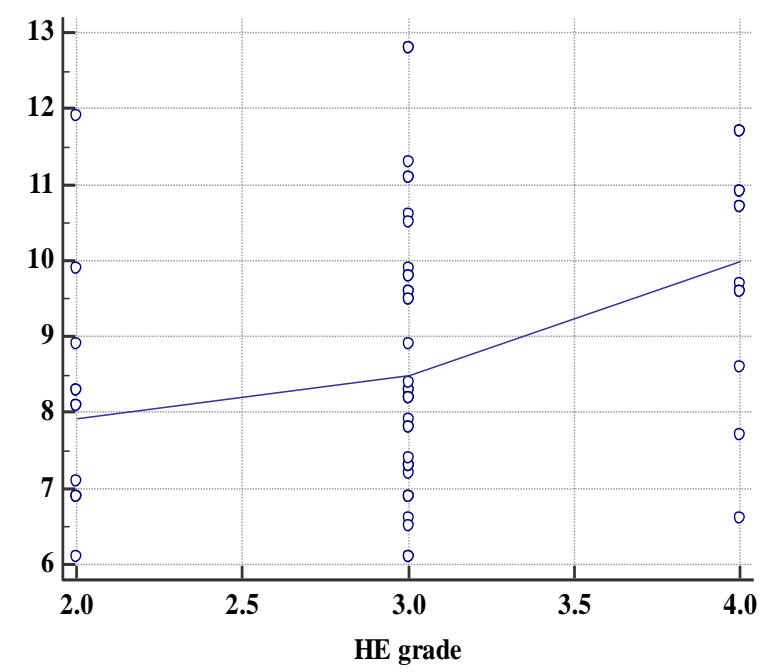

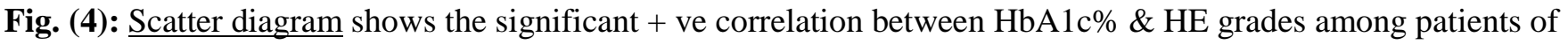
group I.

\section{DISCUSSION}

$\mathrm{HE}$ is a life-threatening neuropsychiatric condition, which may lead to obvious disorientation up to deep coma and death ${ }^{(15)}$. The smitten patients manifested with intellectual, emotional, psychomotor, behavioral, and fine motor functions. Furthermore, it is a crucial factor in the determination of the cirrhotic patient's quality of life. In contrast, liver has a pivotal impact in glucose metabolism counterpart glycogen storage, throughout the fed state, and glycogenolysis and gluconeogenesis to enhance glucose production during fasting ${ }^{(\mathbf{1 6})}$.

It was explicitly evident that there was an association between liver disorders and disturbance of glucose metabolism whereas patients with T2DM have a higher risk of death from chronic liver disorders relative to other patients ${ }^{(17)}$. Throughout literature search, some studies had addressed the association between HE and T2DM. However, these studies were of limited sample size and retrospective design. Thereafter, the current study was performed to overcome these limitations ${ }^{(\mathbf{1 8})}$.

Our results revealed that the age of the patients differed substantially between both groups. Diabetic patients experienced a lower prevalence of grades A and $\mathrm{B}$, whilst they showed a higher incidence of grade $\mathrm{C}$ of Child-Pough classification relative to non-diabetic cases. Additionally, diabetic patients showed a higher incidence of Grades II, III, and IV of HE. Subsequently, there were a statistically significant positive association between FBS and HBA1C\% with the grades of HE. On the one hand, Butt et al. ${ }^{(4)}$ notified that diabetic older candidates had a higher risk and severity of development $\mathrm{HE}$ whereby both age and diabetes were a potential risk of HE. In addition, diabetics had a highly risk to present with advanced grades of $\mathrm{HE}$ well beyond other patients. Similarly, Sigal et al. ${ }^{(19)}$ investigation revealed that HE presented in more than $90 \%$ of diabetic candidates, whilst it was approximately $75 \%$ among non-diabetic patients. This association may be evolved as a resultant effect of autonomic neuropathy which enhanced the occurrence of disturbed motility of the gastrointestinal tract with a considerable effect in the production of ammonia, over-growth of the intestinal bacteria and constipation ${ }^{(20)}$. These factors contributed significantly in ammonia production, which proved to be the most important variable in the existence of $\mathrm{HE}^{(\mathbf{1 9}, \mathbf{2 1})}$.

This study had numerous constringes, which may alter its results. For instance, the lack of randomization and the significant heterogeneity between the included participants regarding some demographic characteristics, and the obscurity of sample randomization and calculation may have a potential effect on the evidence of the study.

\section{CONCLUSIONS}

Egyptian diabetic patients have a potential risk of developing $\mathrm{HE}$ among cirrhotic liver patients relative to non-diabetic candidates. Thereafter, these patients should be subjected to close geriatric care and appropriate control of their blood glucose parameters to avoid poor prognosis. However, quasi-randomized or highly randomized clinical trials with proper calculation of sample size are necessary to overcome the co-existing limitations of the present investigation. 


\section{REFERENCES}

1. Abd-Elsalam S, Elwan N, Soliman H, Ziada D, Elkhalawany W, Salama M et al. (2018): Epidemiology of liver cancer in Nile delta over a decade: A single-center study. South Asian J of Cancer, 7 (1): 24.

2. Romero-Gómez M, Boza F, Garcıa-Valdecasas MS, Garcıa E, Aguilar-Reina J (2001): Subclinical hepatic encephalopathy predicts the development of overt hepatic encephalopathy. The Am j of Gastroenterol., 96 (9): 271823.

3. Gad YZ (2012): precipitating factors of hepatic encephalopathy: An experience at Mansoura Specialized Medical Hospital, Egypt. Ann of Tropical Med and Public Health,5 (4): 330.

4. Butt Z, Jadoon NA, Salaria ON, Mushtaq K, Riaz IB, Shahzad A et al. (2012): Diabetes mellitus and decompensated cirrhosis: Risk of hepatic encephalopathy in different age groups. J of Diabetes, 5 (4): 449-55.

5. Garcia-Compean D, Jaquez-Quintana JO, GonzalezGonzalez JA, Maldonado-Garza H (2009): Liver cirrhosis and diabetes: risk factors, pathophysiology, clinical implications and management. World J of Gastroenterol., 15 (3): 280 .

6. Gundling F, Seidl H, Strassen I, Haller B, Siegmund T, Umgelter A et al. (2013): Clinical manifestations and treatment options in patients with cirrhosis and diabetes mellitus. Digestion, 87 (2): 75-84.

7. Baffy G (2012): hepatocellular carcinoma in type 2 diabetes: more than meets the eye. Nature Publishing Group. The Am J of Gastroenterol.,107(1)53-5

8. Kumar $\mathbf{R}$ (2018): Hepatogenous diabetes: An underestimated problem of liver cirrhosis. Indian $\mathrm{J}$ of Endocrinol and Metabol., 22 (4): 552.

9. Ampuero J, Ranchal I, del Mar Díaz-Herrero M, Del Campo JA, Bautista JD, Romero-Gómez M (2013): Role of diabetes mellitus on hepatic encephalopathy. Metabolic brain disease , 28 (2): 277-9.

10. Garcovich M, Zocco MA, Roccarina D, Ponziani FR, Gasbarrini A (2012): Prevention and treatment of hepatic encephalopathy: focusing on gut microbiota. World $\mathrm{J}$ of Gastroenterol., 18 (46): 6693.
11. Kalaitzakis E, Olsson R, Henfridsson P, Hugosson I, Bengtsson M, Jalan $\mathrm{R}$ et al. (2007): Malnutrition and diabetes mellitus are related to hepatic encephalopathy in patients with liver cirrhosis. Liver Int., 27 (9): 1194-201.

12. Sturgeon JP, Shawcross DL (2014): Recent insights into the pathogenesis of hepatic encephalopathy and treatments. Expert review of Gastroenterol \& Hepatol., 8 (1): 83-100.

13. Vilstrup H, Amodio P, Bajaj J, Cordoba J, Ferenci P, Mullen KD et al.(2014): Hepatic encephalopathy in chronic liver disease: 2014 Practice Guideline by the American Association for the Study of Liver Diseases and the European Association for the Study of the Liver. Hepatol., 60 (2): 715-35.

14. Pugh R (1973): Preoperative assessment of patients with liver disease. Br J of Surg., 60 (1): 646-9.

15. Butt Z, Jadoon NA, Salaria ON, Mushtaq K, Riaz IB, Shahzad A et al. (2013): Diabetes mellitus and decompensated cirrhosis: risk of hepatic encephalopathy in different age groups. J Diabetes, 5 (4): 449-55.

16. Arshad MF, Butt Z, Mushtaq K, Salaria O (2016): Impact of diabetes mellitus on frequency and severity of hepatic encephalopathy in liver cirrhosis. Society for Endocrinol BES., 2 (44) :102.

17. Zoppini G, Fedeli U, Gennaro N, Saugo M, Targher G, Bonora E (2014): Mortality from chronic liver diseases in diabetes. Nature Publishing Group. The Am J of Gastroenterol., 109(7)1020-5

18. Shaheen E-S, Elshazly HM, Allah NA (2018): Hepatic encephalopathy in patients with diabetes mellitus. J of Med in Sci Res., 1 (4): 227.

19. Sigal SH, Stanca CM, Kontorinis N, Bodian C, Ryan E (2006): Diabetes mellitus is associated with hepatic encephalopathy in patients with HCV cirrhosis. The Am J of Gastroenterol., 101 (7): 1490.

20. Jepsen P, Watson H, Andersen PK, Vilstrup H (2015): Diabetes as a risk factor for hepatic encephalopathy in cirrhosis patients. J of Hepatol., 63 (5): 1133-8.

21. Ampuero J, Ranchal I, del Mar Diaz-Herrero M, del Campo JA, Bautista JD, Romero-Gomez M (2013): Role of diabetes mellitus on hepatic encephalopathy. Metab Brain Dis. , 28 (2):277-9. 